rev.relac.int.estrateg.segur.8(1):235-266,2013

\title{
SOLUCIÓN A LA MEDITERRANEIDAD DE BOLIVIA: UNA PROPUESTA DESDE CHILE*
}

\author{
Alain Carrier** \\ Eduardo Tellez ${ }^{* *}$ \\ Fernando Villamizar ${ }^{* * *}$
}

\section{RESUMEN}

Tras la firma del Tratado de 1904 suscrito entre Chile y Bolivia, este último Estado se quedó sin una salida soberana al océano pacífico. El presente artículo da cuenta de cómo Chile a lo largo del siglo XX ha tenido como política de Estado buscar alguna fórmula para brindarle acceso al mar a Bolivia. Además, este artículo presenta una propuesta para solucionar la mediterraneidad de Bolivia, basada en la experiencia del Tratado Antártico de 1959, y finalmente analiza las relaciones de poder involucradas que facilitarían o impedirían una solución.

Palabras clave: Tratado de 1904 Chile y Bolivia, Tratado Antártico.

* El presente artículo es una reflexión fruto del Seminario "La intangibilidad de los tratados internacionales y el tratado de 1904 entre Chile y Bolivia", llevado a cabo el jueves 14 de junio de 2012 en Santiago de Chile en la Universidad Bernardo O’Higgins y que contó con la participación de expositores chilenos, bolivianos y colombianos.

** Director de Investigación y Relaciones Internacionales, Universidad Bernardo O’Higgins. Investigador del Observatorio Regional de Paz y Seguridad (ORPAS) de la Universidad Bernardo O’Higgins. Profesor Universidad de los Lagos. Doctor en Ciencia Política. acarrier@ubo.cl.

*** Director e investigador del Centro de Estudios Histórico de la Universidad Bernardo O’Higgins. Doctor en Historia. etellez@ubo.cl

**** Investigador del Observatorio Regional de Paz y Seguridad (ORPAS) de la Universidad Bernardo O’Higgins. Doctor en Ciencia Política y Sociología.fvillamizar@ubo.cl 


\title{
SOLUTION TO LANDLOCKED BOLIVIA: A PROPOSAL FROM CHILE
}

\begin{abstract}
After the signing of the 1904 Treaty between Chile and Bolivia, the former was left without a sovereign outlet to the Pacific Ocean. This article gives an account of how Chile throughout the twentieth century has had as a State policy, finding a formula to give Bolivia access to the sea. In addition, this paper presents a proposal to solve Bolivia's landlocking, based on the experience of the Antarctic Treaty of 1959 and finally, analyzes the power relations involved that facilitate or impede a solution.
\end{abstract}

Keywords: Treaty of 1904 between Chile and Bolivia, Antarctic Treaty.

\section{SOLUÇÃO PARA A MEDITERRANEIDADE DA BOLÍVIA: UMA PROPOSTA DESDE O CHILE}

\section{RESUMO}

Após a assinatura do Tratado de 1904 entre o Chile e a Bolívia, este último Estado foi deixado sem uma saída soberana para o Oceano Pacífico. Este artigo descreve como o Chile no decorrer do século XX manteve uma política de Estado a fim de encontrar uma fórmula para dar à Bolívia um acesso ao mar. Além disso, este trabalho apresenta uma proposta para resolver a mediterraneidade da Bolívia, com base na experiência do Tratado Antártico de 1959 e, finalmente, analisa as relações de poder envolvidas que facilitaria ou impediria uma solução.

Palavras-chave: Tratado de 1904 entre o Chile e a Bolívia, Tratado Antártico.

\section{INTRODUCCIÓN}

El principio "pacta sunt servanda" es un elemento fundamental del Derecho Internacional Público (Shaw, 2010: 903), de suerte que sin él no existiría un Derecho Internacional, o como afirma Díez de Velasco "(...) sólo puede ser excluido del Derecho Internacional al costoso precio de destruir este último como ordenamiento jurídico" (2007: 206). En ese sentido, la Corte Internacional de Justicia, a través diversos fallos, ha aplicado este principio de forma muy rigurosa, como por ejemplo en el asunto Kasikili/Sedudu (International Court of Justice Reports, Judgment of 13 December 1999, ICJ. Rep. 1045) o la Decisión Preliminar en el caso Nicaragua/Colombia (International Court of Justice, Judgement of 13 December 2007, Summary 2007/5). 
Con esos y otros antecedentes en mente, célebres juristas chilenos (Llanos, 2007: 181 y ss.) y bolivianos (Andaluz, 2002) han concluido que el Tratado de 1904 entre Chile y Bolivia es completamente válido, y en consecuencia debe cumplirse a cabalidad. A su vez, ocurre algo equivalente con el Tratado de 1929 entre Chile y Perú, y su Protocolo Complementario ${ }^{1}$, de manera tal que Chile no ha podido dar una salida al mar a Bolivia sobre territorios otrora peruanos, pese a que lo ha intentado al menos en cinco ocasiones (1895, 1920, 1926, 1950 y 1975).

Ante esta situación surge el problema de investigación que queremos abordar en el presente artículo: ¿no habrá algún mecanismo que permita dar salida al mar a Bolivia sin afectar los Tratados de 1904 y de 1929? La propuesta que se quiere hacer está basada en el éxito del régimen del Tratado Antártico y pretende que todas las partes vean satisfechas en buena medida sus intereses. Para ello, primero se abordará el contexto histórico en que se enmarcan los Tratados de 1904 y 1929, así como las propuestas chilenas para darle a Bolivia salida al mar. En segundo lugar, se analizará el régimen del Tratado Antártico y cómo este se podría constituir en un ejemplo para solucionar el problema de la salida al mar para los bolivianos; y finalmente se hará un análisis a la luz de las implicaciones políticas de la propuesta.

\section{MARCO HISTÓRICO DEL CONFLICTO LIMÍTROFE ENTRE CHILE Y BOLIVIA}

Aunque las relaciones exteriores de Chile con la altiplánica república de Bolivia, nacida en 1825 tras la finalización de la hegemonía española en América en lo que se había conocido como Alto Perú o Provincias Altas, fueron joviales durante más de tres lustros, comenzaron a deteriorarse rápidamente a partir de 1843. Esto ocurrió cuando la legación boliviana destacada en Santiago, a través de su ministro plenipotenciario Casimiro Olañeta, presentó a la cancillería chilena una encendida reclamación diplomática por lo que conceptuaba una flagrante transgresión al principio del uti possidetis juris de 1810 en lo que se refiere a las fronteras que ambas repúblicas mantenían en el desierto o despoblado de Atacama. La demanda boliviana buscaba revertir el alcance de una ley promulgada recientemente por el gobierno chileno que en la práctica extendía la frontera chilena septentrional, hasta por lo menos la latitud del paralelo 23 S., en la profundidad del desierto atacameño.

Esa protesta formal fundó el estilo de la discusión bilateral. Olañeta y varios de los ministros plenipotenciarios alto-peruanos que le siguieron provenían de la docta Universidad de San Francisco Javier de Chuquisaca (Sucre), y desde el comienzo del litigio destacaron por el brillo

1. El artículo primero del Protocolo Complementario establece que: "Los Gobiernos del Perú y de Chile no podrán, sin previo acuerdo entre ellos, ceder a una tercera potencia la totalidad o parte de los territorios que, en conformidad al Tratado de esta misma fecha, quedan bajo sus respectivas soberanías, ni podrán, sin ese requisito, construir, a través de ellos, nuevas líneas férreas internacionales." 
de la argumentación jurídica que exhibieron ante los plenipotenciarios designados por la Moneda $^{2}$. Esa virtud llevó a que los medios ilustrados de Chile, con cierta sorna, acuñaran el motete de doctores de Chuquisaca para referirse a estos diplomáticos, hubieran o no pasado por sus claustros. La tesis medular de los doctores señalaba que entre los territorios coloniales de la antiquísima Real Audiencia de Charcas -también llamada de la Plata o Chuquisaca-, cuya heredera legítima era la república de Bolivia, se contaba la práctica totalidad del desierto de Atacama.

Habiendo promulgado la administración del presidente Manuel Bulnes, el 31 octubre de 1842, una ley de nacionalización de los depósitos de guano de las costas de la provincia de Coquimbo y el litoral atacameño ${ }^{3}$, mayormente concentrados en la Península de Mejillones (latitud de la bahía $23^{\circ} 04^{\prime}$ ), Olañeta puso en cuestión la legalidad de la norma que excedía el límite norte de Chile, que fijó a la altura del paralelo 26, en inmediaciones del río Salado 4 . El ministro boliviano enderezó la disputa hacia la validación de los títulos históricos y los antecedentes jurídicos de origen colonial. Ese enfoque marcó la línea central de la discusión. En los siguientes veinte años ella pareció más un debate entre historiadores, agrimensores y cosmógrafos deslumbrados por su propio repertorio de pruebas que de diplomáticos apremiados por construir un estatuto fronterizo admisible para ambas partes.

Para 1845, la cancillería santiaguina había terminado de redondear su propia posición ante el uti possidetis. En la Memoria que Manuel Montt, Secretario de Estado en la Cartera del Exterior, presentó ante las cámaras legislativas aquel año, la soberanía chilena aparecía extendida varios grados al norte de la bahía de Nuestra Señora (Paposo). Echando mano de una inesperada mapoteca y de otros papeles oficiales, entre los que se contaban el Plano General del Reino de Chile (1793), delineado por el cosmógrafo limeño Andrés Baleato de orden del Virrey del Perú Gil de Taboada y Lemus ${ }^{5}$, y la Carta esférica de las costas del Reino de Chile comprendidas entre los paralelos de los 38 y 22 de latitud Sur. Levantada por orden del Rey en el año de 1790 por varios oficiales de su Real Armada; presentada a S. M. por mano del Exmo. Sr. Don Juan de Lángara, Secretario de Estado y del Despacho Universal de Marina. Año de 1799, dejó establecida la posición de su gobierno respecto del uti possidetis de 1810.

2. Sede oficial del gobierno de Chile.

3. Boletín de las leyes y de las ordenes y decretos del gobierno, lib. X, núm. 10, Huaneras de Coquimbo, Santiago, 31 de octubre de 1842, ley 77, pp. 299-300.

4. Nota de C. Olañeta al ministro de Relaciones Exteriores de Chile Ramón L. Irarrázabal, 30 de enero de 1842, pp. 15-18, que figura en la "Cuestiones de límites entre Chile y Bolivia", recopilación de la documentación intercambiada entre los gobiernos de Chile y Bolivia en torno a la disputa de límites que sostenían en Atacama entre 1843 y 1859 , inserta en la Memoria que el ministro de estado en el departamento de relaciones exteriores presenta al congreso nacional de 1862, Santiago de Chile, Imprenta Nacional, pp. 14-120. En adelante se citará como CLChB.

5. Carta esférica de las costas del Reyno de Chile comprendidas entre los paralelos 38 y $22^{\circ}$ de latitud Sur/ Levantada de orden del Rey en el año 1790 por varios oficiales de su Real Armada, presentada a S.M. por mano del Exmo. Señor D. Juan de Langara; Juan Moreno Tejada la grabó; F. Bauzá la delineó; P. M. Gangoiti la escribió. Chile. E (Costa). Cartas náuticas. 1799. (Madrid: Dirección de Hidrografía, 1799). (S 21ํ45'-38o / O 63o-7520'). (Registro nro. 82620), PR Real Biblioteca. 
De acuerdo con ello: "No solo pues (según aparece de documentos auténticos) pertenece a Chile la bahía de Nuestra Señora, sino la bahía de Mejillones y Cobija, y en una palabra, toda la costa hasta la desembocadura del río Loa" (Montt, 1845: 375). En lo sucesivo, asentó, en las cuestiones de límites, a diferencia de lo obrado hasta allí por los enviados alto-peruanos que anteponían ante todo los datos de cronistas y tratadistas "privados" (no oficiales), su cancillería se apoyaría en la documentación que por su carácter oficial -por emanar de la corona española- tuviera fuerza pública (Montt, 1845: 373-74).

La misión diplomática del Altiplano, metáfora con la cual hasta hoy en día los círculos chilenos suelen aludir a Bolivia por el peso político y geográfico que esa región andina tiene en esa nación, quedó momentáneamente a la defensiva. La invocación de las viejas relaciones históricas coloniales, las cédulas, las reales provisiones y la recargada legislación indiana no zanjó, sin embargo, la controversia. Ambos contendientes encontraron en aquellas fuentes de antaño nada más que la validación de su propia postura. Las cédulas y documentos coloniales relativos a la creación de la audiencia de Charcas, no definieron un límite reconocido con el reino de Chile ni hacen referencia a Atacama6.

Igual ocurrió con los textos fundacionales de las reales audiencias de los $\operatorname{Reyes}^{7}$ (Lima) y de Santiago de Chile ${ }^{8}$. Las ordenanzas de la Recopilación de las leyes de los reinos de Indias (1680), tan traídas y llevadas en el curso de las mutuas alegaciones, tuvieron ese sino. La ley IX, título XV, del libro $2^{\circ}$ de este denso código legislativo dado a imprenta en 1681, concerniente a la audiencia de Charcas o de la Plata, aparecía otorgando a ella una posición en las costas del Mar del Norte (Atlántico) y del Sur (Pacífico), si bien sin decir dónde ni señalar su extensión y deslindes ${ }^{9}$.

Los diplomáticos chilenos vindicaron la ley $\mathrm{V}$, del mismo título y libro, tocante a la audiencia de Lima o los Reyes, que extendía su propio distrito por la franja costera hasta tocar con la frontera del Reino de Chile, estableciendo una colindancia clara entre una y otra ${ }^{10}$. Los doctores de

6. AGI, RP expedida en Lima, en 22 de mayo de 1561, Patronato, leg. 188, ramo 19; RP expedida en Monzón el 4 de octubre de 1563, audiencia de Charcas, leg. 418, lib. I, fols 26ro--66ro우 R.P. firmada en Madrid, el 16 de agosto de 1563, audiencia de Charcas, leg. 418, lib. I, audiencia de Charcas, leg. 418, lib. I, fols. 66 y ss; audiencia de Lima, leg. 569, Lib. XI, fols. 75 y ss.

7. RC dada en Valladolid de 13 de septiembre de 1543, AGI, Audiencia de Lima, leg. 566, tomo 2o, fol.51. También AN, FMV, vol. 29, pza. 2.

8. AGI, Audiencia de Chile, leg. 170, lib. I, fols. 173- 218o remite a la creación de la primera audiencia de Chile, con sede en Concepción (1565-1575), sin dar mayor luz sobre el punto. Igualmente en los documentos de su restablecimiento, ahora con ubicación en Santiago, Audiencia de Chile, leg. 67; en las Consultas al Consejo de Indias, años 1604/1697. Núm. 1, Consejo de Indias, Valladolid, 20.09. 1604; núm. 2, Consejo de Indias, Valladolid, 11 de febrero de 1605, y núm. 3, Consejo de Indias, Valladolid, 22 de abril de 1605, se habla del reino o provincias de Chile sin asignarle distrito, incluida la consulta 3, que acordó restablecer la audiencia chilena.

9. Recopilación de las leyes de los reinos de Indias, 1681, tomo 2º , tít. xv, lib. ii, ley ix, Audiencia y Chancillería Real de la Plata, Provincia de los Charcas, fol. 189v.

10. Ver la nota anterior, esp. ley v, fol. $188 \mathrm{v}$. 
Chuquisaca replicaron oportunamente que los términos de esa misma ley establecían, con todo, que por el sur la audiencia de Lima confinaba con la de la Plata (contradiciendo el pasaje de la misma que la hacía limitar por la costa con la presidencia de Chile) ${ }^{11}$. La ley pertinente al distrito y composición de la audiencia y real cancillería chilena, por su parte, no le fija un linde específico asociado a un accidente natural o a una línea imaginaria que señalaran su límite norte.

Ninguna de estas legislaciones (leyes V, IX y del tít. XV, lib. 2º, de la Recopilación) asignó explícitamente la provincia de Atacama a alguna de las tres presidencias coloniales ${ }^{12}$. Los únicos territorios y puntos que se le reconocen a Charcas en la Recopilación corresponden a la región del Collao, que es enteramente mediterráneo y se extiende desde Atuncana, punto situado en la "hacia la parte de los Charcas" (ley tit. XV, lib. 2013) ${ }^{14}$. Los vacíos y ambigüedades legislativas se intentaron flanquear acudiendo a las crónicas, la cartografía, los códices manuscritos y los relatos dejados por las expediciones científicas acerca del litoral desértico. A la postre, se fraguó una tradición erudita basada en la recitación de los viejos documentos coloniales y el hallazgo de nuevos pergaminos y testimonios de archivo.

La diplomacia y la ciencia histórica alto-peruana acopiaron antecedentes de primera mano que asignaban el desierto de Atacama a Charcas y mostraban al puerto indio de Cobija en posesión de dicha presidencia ${ }^{15}$. La chilena contestó ese catálogo con su propio repertorio de pruebas, que inclúan una serie de actos de soberanía ejercidos en el despoblado, incluido el control administrativo de las poblaciones aborígenes a lo largo de la costa atacameña, como las asentadas en Morro Moreno, algo al norte del lugar en el que después se alzaría la ciudad de Antofagasta ${ }^{16}$.

11. Ley v, fol. $188 \mathrm{v}$.

12. No obstante, se ha confundido muchas veces Atuncana con Atacama por su mera cercanía fonética u ortográfica. No hay tal, como bien lo dejó anotado Diego Fernández el Palatino al describir la geografía de las guerras civiles del Perú en su Primera y segunda parte de la Historia del Perú [1571], destacando que quedaba medio camino del Cusco y Arequipa. Así es cono figura también en el mapa de Willem Janszoon Blaeu bajo el epígrafe Perú (Ámsterdam, c. 1640), que lo ubica no lejos, por el suroeste del lago Titicaca, en el altiplano andino. Era uno de los pueblos principales de la antigua "provincia de los Canas", más tarde integrado al corregimiento de Tinta. Como "corregimiento de indios", Tinta formó parte del corregimiento del Cusco en los siglos XVII y XVIII. No tiene conexión alguna con Atacama. Forma parte de la provincia de Canchis, una de las que componen el actual departamento de Cusco.

13. Recopilación de las leyes de los reinos de Indias, 1681 , tomo 20, tít. xv, lib. ii, que los términos de la ciudad del Cuzco se dividan entre las Audiencias de Lima y la Plata, conforme a esta ley, fol. 190v-191.

14. RP de 30 de noviembre de 1568, audiencia de Lima, leg. 578, lib. li, fols. 276- 277v.

15. Carta de Juan Lozano Machuca, factor de Potosí, al virrey Martín Enríquez, Potosí, 08 de noviembre de 1581, Biblioteca Nacional de Madrid, J58, fol. 145. Padrón y Revisita de Atacama del corregidor Alonso Espejo ordenada por el virrey duque de La Palata, 1683, AGN, Sala IX 7. AGI, audiencia de Charcas, leg. 438.

16. AN, CG, vol. 329, f. 152. Archivo Arzobispado de Antofagasta, 1611/1698 Libro de Varias Hojas repartidas que se recogieron siendo cura propio de este beneficio de Atacama la Baja, el maestro don Bernardo López Sagues... fs. 43. Mercurio Peruano, tomo I, núm. 23 del día 20 de marzo de 1791, Disertación histórica y política sobre el comercio del Perú de José Baquijano y Carrillo, fol. 211. 
A la tesis boliviana según la cual el límite septentrional del reino de Chile estuvo en el paralelo 27 (Copiapó), desde que Pedro de Valdivia fue designado Gobernador Titular en 1548 por Pedro de la Gasca, los tratadistas chilenos opusieron que con los años la jurisdicción chilena creció hacia el paraje del Paposo y alrededores, prácticamente hasta dos grados y medio más al norte, sencillamente porque en la antigua concesión dada por Gasca a Valdivia no se decretó una línea de frontera estática ${ }^{17}$.

La bahía de Nuestra Señora del Paposo habría sido, desde la perspectiva chilena, una de las sólidas avanzadas de su soberanía en los desérticos espacios boreales, lo que en buena medida fue reconocido al nombrarse para ese distrito un diputado territorial que debía administrar justicia a sus pescadores indígenas. La misma corona, se aduce, creó un obispo auxiliar con asiento en Paposo, paraje dependiente del obispado de Santiago ${ }^{18}$. No obstante, la jurisdicción chilena se habría extendido mucho más al norte.

Para refrendarlo, los autores chilenos traen a colación que nuevas comprobaciones certifican que Cobija, la corta rada indígena enclavada no lejos de la barra del Loa, había estado para 1777 bajo la administración aduanera de la real hacienda chilena, con pleno conocimiento de la corona española ${ }^{19}$. Mucho después (1825), se acota que habiendo quedado este fondeadero en el desamparo, Simón Bolívar, pensando en las comunicaciones marítimas con el mundo de la

17. El nombramiento provisorio que el cabildo de Santiago hizo en Valdivia como gobernador de Chile y el de Gasca, que fijan el principio de la gobernación en el grado 27 o en Copiapó, en AGI, Patronato, leg. 92, N. 1, R. 1, "Información de los méritos y servicios de Pedro de Valdivia, gobernador y capitán general de Nueva Extremadura, y su primer descubridor. El licenciado Gasca le dio en gobernación 41 grados de norte a sur y cien leguas de ancho hueste leste". Patronato, 185, R. 25, "Nombramiento gobernador Santiago a Pedro de Valdivia, Chile, (1541), mientras S.M. proveía otra cosa". El documento autentificado en AN, FMV, vol. 25, pza. 16, "Nombramiento de gobernador de Chile dado por la Gasca a Pedro de Valdivia, 22 de abril de 1548". Valdivia confirma esta delimitación inicial en textos oficiales emitidos por él; cfr. AGI, Patronato, leg. 29, R. 1, "Auto de la posesión que tomó Pedro de Valdivia, en nombre del emperador Carlos $\mathrm{V}$, en el puerto de Valparaíso, de la provincia de Santiago del Nuevo Extremo o Chile, y de otros pueblos, cuyo descubrimiento había encomendado al capitán Juan Bautista de Pastene, piloto del navío "San Pedro", Jerónimo de Alderete y a otros. Valparaíso, 3 de septiembre de 1544" y Patronato, leg. 29, R. 2., "Relación de la tierra y costa que descubrió Pedro de Valdivia, electo gobernador y capitán general, en el Nuevo Extremo hasta el Estrecho de Magallanes, en el valle de la Posesión en Copiapó hasta el de Coquimbo; y de la posesión que de ella se tomó. Valparaíso, 3 de septiembre de 1544".

18. AN, CG, vol. 771, leg. 121. Sobre el nombramiento de Rafael Andreu y Guerrero misionero en charcas, Santiago y otros, 26.06.1802, BN, MIHCh, Biblioteca Americana de J. T. Medina, RC del 1 de octubre de 1803 al presidente de Chile comunicando la resolución de poblar el puerto de Paposo, vol. 216, leg. 5537.

19. AGI, audiencia de Chile, leg. 328, Prevenciones que en cumplimiento del cap. 22 de las instrucciones formadas para el establecimiento de las administraciones generales de los reales derechos de almojarifazgo y alcabalas de la capital de Santiago de Chile y del oficio pasado por el señor contador mayor, don Juan Tomás de Echevers, su fecha 13de septiembre del presente año de 1777, a consecuencia de la real orden de 6 de abril del citado año, que previene el establecimiento de las administraciones por su real cuenta para la uniformidad del cobro y manejo de dichos ramos a imitación de la capital en todos los corregimientos de esta gobernación, hace el administrador don Ramón del Pedregal y Mollinedo acompañando las citadas instrucciones y demás providencias que gobiernan dicha administración general para el más efectivo logro de las soberanas intenciones; cfr. la prevención núm. 6. 
recién fundada república boliviana, decidió habilitarlo como primer puerto del Alto Perú, acto que, se critica, sólo podía reflejar la profunda mediterraneidad que había afectado a Charcas durante dos siglos y medio.

Se deja ver que, sobre esos argumentos, la negociación avanzó poco y casi siempre a tientas. La legación boliviana destacada ante la Moneda terminó por consentir que Paposo, situado en los 25ํㅜ $1^{\prime}$ de latitud S., era posesión chilena ${ }^{20}$. La cancillería mapochina ${ }^{21}$, a su vez, pese a propugnar que sus títulos históricos le aseguraban soberanía hasta la desembocadura del Loa, no demandó la desocupación de Cobija, proponiendo una división salomónica del desierto en el paralelo 23 (Mejillones). Bolivia expuso en cambio que la traza limítrofe coincidiera con la latitud de Paposo.

En medio de estos tanteos de solución racional del diferendo, las cosas se salieron de curso sobre el terreno. Contestando en los hechos a lo que consideraba una hostilidad inadmisible ejercida por la autoridad de Cobija contra los barcos y empresarios del guano que operaban en el litoral atacameño con licencias expedidas por el estado chileno, a los cuales se intentó detener, la fragata Chile ocupó Mejillones en 1847, alzando un fortín de vigilancia sobre la bahía ${ }^{22}$. Bajada la tensión y retirada la fuerza ocupante, un piquete boliviano venido de Cobija demolió el baluarte. En 1863 la escuadra chilena se lanzó a la captura de los que su gobierno conceptuaba eran explotadores ilegales de las covaderas nacionales asolando las instalaciones que tenían erigidas en Punta Chacaya, algo al norte de Mejillones. El congreso boliviano contestó la incursión naval autorizando a la presidencia de Bolivia, confiada a José María Achá, a declarar formalmente la guerra a Chile. El conflicto parecía transcurrir ya por la pendiente bélica. En París, el mariscal Andrés de Santa Cruz se dio a la faena de estudiar la adquisición de tres barcos de guerra para enfrentar la contienda con la armada chilena.

Extrañamente no sólo se evitó una reyerta fratricida: tres años después de invocar la protección de Marte ambas repúblicas buscaron la de Minerva y firmaron un primer tratado de límites. Ese giro inesperado tuvo como detonante justamente otra guerra. Producto del activo respaldo en bloque que el gobierno y el pueblo chileno dieron a la república del Perú en el conflicto que mantenía con España, cuya flota en el Pacífico mantenía ocupadas por la fuerza los ricos depósitos guaneros de la islas Chinchas en una clara demostración de prepotencia colonialista,

20. Así se admite en la nota que dirigiera el agente oficial boliviano ante la Moneda, José María Santibáñez, al ministro de relaciones exteriores de Chile, fechada en Santiago el 08 de noviembre de 1858, transcrita en CLChB, p. 55.

21. Adjetivo que se suele dar en la literatura especializada peruano-boliviana a la cancillería y gobierno de Chile con sede en Santiago, cuyo río principal es el Mapocho. Correlativamente, en los escritos chilenos es usual hablar de cancillería o gobierno del Rímac para aludir al Perú, por estar Lima, sede del gobierno de esa república, asentada en las márgenes de dicho río.

22. AN, AMRE, vol. $63 \mathrm{~A}$, informe del capitán Robert Simpson, comandante de la fragata Chile sobre las operaciones en Mejillones y costa aledaña, Cobija, 20 de diciembre de 1847, fs. 48-48v. 
el gobierno de Santiago se vio envuelto en una magna contienda bélica con la división naval hispana, confrontación en la que Perú, Ecuador y Bolivia, regida por Mariano Melgarejo, dictador de ardiente vocación americanista, se le unieron en la empresa de sobrellevarla.

Repentinamente las vallas nacionales se levantaron y los recelos se apagaron. El panamericanismo anegó por un instante los imaginarios nacionales y bañó de fraternidad recíproca a la clase política y a la intelectualidad "decididas a consolidar por este medio la buena inteligencia, la fraternal amistad y los vínculos de alianza intima que las ligan mutuamente, han determinado renunciar a una parte de los derechos territoriales que cada una de ellas, fundada en buenos títulos, cree poseer"; ambas habían decidido firmar el tratado de citas, en cuyo artículo principal quedó establecido "que la línea de demarcación de los límites entre Chile y Bolivia en el desierto de Atacama, será en adelante el paralelo 21 de latitud meridional desde el litoral del Pacífico hasta los límites orientales de Chile, de suerte que Chile por el sur y Bolivia por el norte tendrán la posesión y dominio de los territorios que se extienden hasta el mencionado paralelo 24, pudiendo ejercer en ellos todos los actos de jurisdicción y soberanía correspondientes al señor del suelo", pero en el artículo siguiente se acordaba un condominio.

Según esto, y "no obstante la división territorial estipulada en el artículo anterior", ambas repúblicas "se repartirán por mitad los productos provenientes de la explotación de los depósitos de guano descubiertos en Mejillones y de los demos depósitos del mismo abono que se descubrieren en el territorio comprendido entre los grados 23 y 25 de latitud meridional, como también los derechos de exportación que se perciban sobre los minerales extraídos del mismo espacio de territorio que acaba de designarse". En Mejillones se habilitaría una aduana común destinada a percibir las entradas dejadas por la explotación del guano y la exportación de metales en el territorio de comunidad ${ }^{23}$.

El arreglo de 1866, perfeccionado por otro de 1872 -el tratado Lindsay-Corral- no funcionó en los hechos. Entre otras razones poderosas, alegó Chile, el gobierno de Melgarejo había caído en grave incumplimiento del artículo $2^{\circ}$, dejando sistemáticamente sin declarar las entradas fiscales originadas por la extracción de guano y metales en la zona comportada. Ciertamente, la administración paceña no hizo mucho por dar cumplimiento a un tratado fuertemente fustigado por su oposición interna que vio en él una claudicación de la soberanía nacional.

Una nueva ofensiva diplomática, encabezada en la Paz y Sucre por el ministro chileno, Carlos Walker Martínez, que contó con el beneplácito del presidente de turno, de su canciller, Mariano Baptista, y del congreso boliviano, dejó atrás el acuerdo fracasado fraguando otro, signado el 6 de agosto de 1874, tratado que ponía término al resistido condominio, mantenía la frontera

23 Tratado de límites entre las repúblicas de Chile y la de Bolivia, Boletín de las leyes y de las órdenes y decretos del gobierno, lib. xxxiv, núm. 12, diciembre de 1866, pp. 434-439. 
binacional en el grado 24 y establecía, en su cuarto artículo, que "los derechos de exportación que se impongan sobre los minerales exportados en la zona de terreno de que hablan los artículos precedentes, no excederán la cuota de la que actualmente se cobra, y las personas, industrias y capitales chilenos no quedarán sujetos a ms contribuciones de cualquiera clase que sean que las que al presente existen. La estipulación contenida en este artículo durará por el término de veinticinco años".

Bolivia quedaba comprometida a habilitar los puertos de Mejillones y Antofagasta, que tomaban incremento tras el hallazgo de mantos salitreros en las cercanías de su litoral -cuya explotación principal estaba confiada a la Compañía de Salitres de Antofagasta- y del gran yacimiento argentífero de Caracoles, cuya posición dentro de la zona de explotación binacional (entre los paralelos 23 y 24), debería determinarse por una comisión de expertos posteriormente ${ }^{24}$.

El tratado de 1874, construido para edificar la paz, terminó incitando la guerra. El 14 de febrero de 1878 la asamblea constituyente de Bolivia dio su aprobación a un proyecto de ley presentado por el gobierno del presidente Hilarión Daza, que había derribado del poder al anterior presidente constitucional, Félix Frías, mediante golpe de estado, orientado a establecer una contribución de 10 centavos por quintal de salitre exportado en el litoral. La Compañía de Salitres, temiendo que esa gabela fuera la primera de otras muchas, resistió la medida que, propugnaba, atentaba contra lo establecido en el artículo cuarto del tratado de límites de 1874 y el concordato que la empresa firmara con el ejecutivo boliviano en escritura pública levantada en Sucre el 29 de noviembre de 1873 (Ahumada Moreno,1884: 9).

El gobierno santiaguino compartía esa interpretación de una cláusula que a su entender vedaba cualquier alza de tributos por un cuarto de siglo. La misión chilena en la Paz no tuvo, con todo, éxito en su tentativa de convencer a la administración del general Daza de derogar la ley de febrero. A dicha altura, para esta cancillería la desavenencia se había trocado en una cuestión de honor nacional. En esa tesitura, las propuestas chilenas de acudir al arbitraje de una tercera potencia (el emperador de Brasil) fueron desestimadas por Daza (Querejazu, 2009:168). Llegó, demuestra Roberto Querejazu, a destituir a su ministro del exterior, Martín Lanza, por el mero hecho de haber planteado la posibilidad de acudir al arbitraje para resolver el diferendo con Chile.

La opción que él y su gabinete adoptaron fue la de radicalizar el conflicto. El 1 de febrero de 1879 dictó un decreto que llevaba la firma de todos sus ministros rescindiendo el contrato que la Compañía de Salitres mantenía con el ejecutivo boliviano desde 1873 y sus privilegios anejos.

24. Tratado de límites entre la república de Chile y la de Bolivia, Boletín de las leyes y de las órdenes y decretos del gobierno, lib. xliii, núm. 10. $2^{2}$ vol., octubre de 1875, pp. 524-530. 
Daza reivindicó la riqueza recuperada como propiedad nacional y ordenó sacar a remate las propiedades de la compañía.

La subasta no alcanzó a hacerse. El 14 de febrero de 1879, un escalón de desembarco chileno ocupó Antofagasta y Mejillones, dentro de lo que la Moneda definió como "territorio reivindicado", partiendo del presupuesto de que antes de los tratados de 1866 y 1874 consideraba la región extendida entre los grados 23 y 24 parte de su herencia colonial. Dado que Bolivia declaró la guerra a Chile el 1 de marzo, la armada y el ejército chileno se apoderaron de Calama y el cantón interior de San Pedro de Atacama, con su entorno oriental, la Puna atacameña, y en los puertos de Cobija y Tocopilla. La señal era terminante. Todo el territorio desértico hasta las márgenes del Loa quedaba bajo tuición chilena.

La guerra se hizo al cabo triangular. El gobierno de Lima, presidido por Mariano I. Prado, se conmovió hondamente. Perú desde 1873 mantenía un tratado de defensa confidencial con Bolivia, originado por los temores con que los estadistas limeños habían ido mirando sus relaciones con Chile tras el término de la guerra federada que ambas repúblicas sostuvieran con España en $1866^{25}$. Los progresos del capital, la industria y la población chilena en el despoblado de Atacama y el notable reforzamiento mediante dos blindados adquiridos en Inglaterra, de su flota de guerra, fueron entendidos como ruptura, en favor de Santiago, del equilibrio geopolítico en el Pacífico y una evidente amenaza geo-económica a los intereses salitreros del estado peruano. Este, desde la presidencia de Manuel Pardo (1872-76) se había empeñado en poner bajo control público el salitre de Tarapacá, logrando finalmente ponerlo bajo un monopolio fiscal (1875).

Mas ese plan parecía verse desafiado por los cantones nitrateros de Antofagasta, en notable alza productiva, producto de las fuertes inversiones en capital financiero y tecnología avanzada efectuadas por corporaciones chilenas, asociadas a empresarios de origen británicos. Tales consorcios se movían con una implacable lógica competitiva, propia de entidades capitalistas que eran amigables con los monopolios privados pero no con los estatales, lo que no podía ser mirado con tranquilidad por los estadistas limeños. En transitoria crisis económica, al igual que Chile y Bolivia, el gobierno del Rímac, en todo caso, no quería abiertamente la guerra a fines de 1878. Sin embargo, Daza precipitó el casus foederis contemplado en el artículo 4음 del tratado secreto de 1873, que lo obligaba en la forma a apoyar a su contraparte en caso de enfrentar una guerra exterior ${ }^{26}$.

25. Tratado de alianza defensiva entre las repúblicas de Perú y Bolivia de 6 de agosto de 1873 (mss.), archivo particular de E. Téllez, f. 1.

26. Tratado de límites entre la República de Chile y la de Bolivia, Boletín de las leyes y de las órdenes y decretos del gobierno, lib. xliii, núm. 10. 2º vol., octubre de 1875, 524-530. 
La administración de Prado no paró en mientes el riego que corría al ofrecer a Chile su mediación en el conflicto: se constituía en poder arbitral del mismo pese a no serlo puesto que estaba concertado por un pacto solemne que nunca hizo público con uno de los contendores, circunstancia que anulaba de raíz la gestión en su carácter de no interesada. Así y todo, destacó en Santiago en misión especial al ministro José Antonio Lavalle que, previsiblemente, no pudo explicar la anómala convivencia bélica que amarraba jurídicamente a Lima con el gobierno paceño, cuando fue interrogado por el canciller chileno sobre la materia. Destapado el asunto, el representante de Santiago en Lima intentó vanamente obtener del gobierno de Prado que intentara tomar el único sendero que quedaba para salvar la paz del despeñadero, declarando la neutralidad del Perú en el diferendo entablado, alternativa resistida hasta el fin por su administración. El 5 de abril de 1879 Chile declaró a las repúblicas confederadas por el tratado defensivo de 1873 una guerra que con la dramática derrota de ambas en los campos de batalla.

De retorno de la guerra a la política, Chile firmó con Perú el tratado de Ancón (1883), que le dejó a perpetuidad en posesión de la antigua provincia peruana de Tarapacá y por diez años las de Tacna y Arica, cuya pertenencia definiría en un plebiscito su población al terminar ese lapso ${ }^{27}$. Bolivia se allanó a firmar una tregua por cien años con Chile, dejando en posesión indefinida a este del que fuera otrora su departamento Litoral, y que la administración civil chilena prefería denominar provincia de Antofagasta, cuyos límites iban, en sentido de oeste a oriente, desde la línea de costa hasta la cordillera y Puna de Atacama, y de norte a sur desde las márgenes del Loa hasta el límite con el departamento de Taltal ${ }^{28}$.

La paz definitiva llegó no obstante mucho antes. Con todo, en los 20 años que demoró establecerla retoñó en Chile, en el mismo año cruento de 1879, una estrategia geopolítica cuyo mentor original fue Domingo Santa María, alto estadista que llegaría después a la presidencia de la nación. Fue la bien llamada "política boliviana". Santa María y quienes la respaldaban (v.gr. Eusebio Lillo, Justiniano Sotomayor, Gabriel René Moreno, entre otros), creían fatídico para los intereses de Chile encerrar a Bolivia entre montañas, negándole una salida natural al Pacífico. Tomando pie en la historia colonial de Hispanoamérica, divisaban en Arica y su zona adyacente como una evidente vía de acceso del país altiplánico al mar. El núcleo ariqueño fue efectivamente en el pasado ibero el puerto de Charcas en el oeste.

Entregárselo una vez conquistado al Perú, antes que se chilenizara demográfica, política y culturalmente, no iría en mengua de Chile, que todavía no miraba esa posesión como suya, esto

27. Tratado de paz y amistad entre las Repúblicas de Chile y el Perú, 20 de octubre de 1883, Diario oficial de la República de Chile, núm. 2.129, Santiago de Chile, 21 mayo 1884, y Boletín de las leyes y de las órdenes y decretos del gobierno, lib. liii, núm. 5, mayo de 1885, pp. 372-380.

28. Pacto de tregua entre Chile y Bolivia, 4 de abril de 1884, Diario oficial de la República de Chile, núm 2.289, Santiago de Chile, 4 diciembre 1884, y Boletín de las leyes y de las órdenes y decretos del gobierno, lib lii,.núm. 12, diciembre de 1884, pp.1379-1383. 
es, no ligada sentimentalmente a la etnicidad y la geografía nacional por lazos firmes. Negarle esa solución a Bolivia equivalía a asfixiarla y mantener vivo un secular anti-chilenismo, odiosidad que conservaría encendido un foco de pugna y guerra diplomática entre La Paz y Santiago en el siglo venidero. Mirando a esto, Santa María se las ingenió para, mediante los oficios de dos relevantes emisarios bolivianos, Salinas Vega y Gabriel René Moreno, acercarse a Daza a fines de 1879 y tentarlo con la oferta de desechar su alianza con Perú y aceptar la de Chile a cambio de obtener la cesión de Arica.

Se partía del principio que teniendo Chile ocupada ya la provincia Tarapacá con miras a incorporarlo a sus fronteras no cabía posibilidad alguna de retornar a Bolivia la de Antofagasta, ante la imposibilidad de interrumpir la continuidad de los territorios del extremo norte que acababa de conquistar en sangrienta y terrible justa. Hilarión Daza consintió en aceptar este negociación oficiosa cuyos hilos movía tras bambalinas Santa María, plan que acercaba a la nación altiplánica, después de cuatro siglos, a su Tierra Prometida (Arica), puerto ambicionado por la presidencia de Charcas desde su fundación (Téllez, 1988: 143-44). Mas el entendimiento fue torpedeado por los dirigentes peruanos de la guerra que intuyeron rápidamente la maniobra chilena y por las veleidades del propio Daza que trepidaba después de avanzar en el acuerdo. Frustrada, la "política boliviana" fue retomada no obstante en otra gestión, perdida finalmente en 1880, por Eusebio Lillo que promovió, autorizado por su gobierno, la cesión a Bolivia, en cambio de la entrega del departamento Litoral, de las provincias peruanas de Moquegua y Tacna, además de una plena libertad de comercio por la costa comprendida entre Camarones y Antofagasta (Téllez, 1988).

Esos desengaños enterraron la iniciativa urdida magistralmente por Santa María al inicio de la guerra del Pacífico. Con todo, ella sólo quedó insepulta. Tras la tregua de 1884, sucesivas presidencias de Chile se abocaron a resucitarla. La cuestión de Tacna y Arica, aún no definida por el plebiscito acordado en Ancón, pues este se había ido aplazando en medio de las encontradas posiciones mantenidas por las cancillerías de Santiago y Lima sobre los aspectos jurídicos y materiales de su ejecución, seguían siendo, desde la perspectiva de cierta parte de la clase política chilena, un presente griego.

Ese litigio acumulaba peligrosas tensiones con Perú e incitaba otras muchas con Bolivia, deseosa de obtener alguna o ambas de las dos regiones en disputa. Y esto en momentos en que la crisis de relaciones entre Chile y Argentina por la demarcación de la fronteras patagónica y de la Puna de Atacama, concedida unilateralmente por Bolivia a Argentina después que fuera ocupada por Chile, entraban en una dinámica que podía terminar en otra guerra fronteriza imprevisible. En ese clima, se concretaron los auspiciosos tratado de 1895. Estando a la cabeza del ministerio del exterior de Chile, Luis Barros Borgoño, y Heriberto Gutiérrez como encargado de la legación de Bolivia en Santiago, se arribó a un concordato preliminar por iniciativa del segundo. 
El 18 de mayo de 1895 ambos estados suscribían un sorpresivo tratado de paz y amistad que confería a Chile la soberanía perpetua sobre el territorio de Antofagasta. Se acordó, con la misma fecha, no obstante, un instrumento jurídico que era una verdadera permuta de territorios. Por dicha razón se rotuló el arreglo como tratado especial de transferencia de territorio. Conforme a él (art. 1), Chile se comprometía a transferir a Bolivia las provincias de Tacna y Arica, de ganarlas en el postergado plebiscito concertado en el tratado de Ancón. Se exceptuaba del acuerdo la región que se extendía desde la quebrada de Camarones a la de Vítor, que Chile retendría.

Bolivia indemnizaría a este dicha cesión con cinco millones de pesos de plata. El cuarto artículo señalaba que "Si la República de Chile no pudiese obtener en el plebiscito o por arreglos directos la soberanía definitiva de la zona en que se hallan las ciudades de Tacna y Arica, se compromete a ceder a Bolivia la caleta de Vítor, hasta la Quebrada de Camarones u otra análoga", recibiendo de todas formas los cinco millones de pesos de plata por concepto de indemnización ${ }^{29}$.

Pese a que en apariencia los pactos de mayo eran favorables a las pretensiones bolivianas, encontraron fuerte oposición en Sucre, sede del poder legislativo del Altiplano, particularmente entre la de signo liberal que cuestionó la cesión permanente del antiguo litoral a cambio de la hipotética entrega de regiones sobre los cuales Chile no poseía soberanía plena. A la vez, censuraba que Santiago abordara en convenciones separadas una materia de naturaleza indivisible (la cesión perpetua de la provincia de Antofagasta y el territorio autónomo por el cual se canjearía).

Así resultaba que por el primer protocolo Chile ganaba para la eternidad una región otrora perteneciente a Bolivia, mientras que en el segundo sólo le cedía un territorio costero a título precario. No habiendo sido ratificado el tratado Borgoño-Gutiérrez por el parlamento altiplánico, las cancillerías comprometidas intentaron salvarlo en diciembre de 1895 mediante un protocolo adicional que establecía un plazo dos años a la obligación asumida por Chile de conceder a su contraparte un puerto soberano a Bolivia, firmado por el ministro chileno ante esa nación, Juan G. Matta y el canciller boliviano, Emeterio Cano.

De no cumplirse aquella cláusula en el plazo estipulado, quedaría sin efecto (art. 2) la cesión del litoral a Chile convenida en el tratado de Transferencia. El cuarto dejaba a firme que si Chile no consiguiera obtener el puerto y los territorios comprometidos "y llegase el caso de cumplir las otras previsiones del Pacto, entregando Vítor u otra caleta análoga, no se dará por llenada dicha

29. Tratados de paz y amistad, transferencia de territorios y de comercio entre Chile y Bolivia. Se aprueba. Boletín de las leyes y de las órdenes y decretos del Gobierno, lib lxiv, núm. 9, septiembre de 1895, p. 730; y Diario Oficial de la república de Chile, núm. 5298, Santiago de Chile, 31 de diciembre de 1895. Ver además, Tratado de paz y amistad entre las repúblicas de Chile y de Bolivia, Boletín de las leyes y de las órdenes y decretos del gobierno, lib. Ixv, núm. 5, mayo de 1895, pp. 366-371. 
obligación de parte de Chile, sino cuando entregue un puerto y zona que satisfagan ampliamente las necesidades presentes y futuras del comercio e industrias de Bolivia" (Téllez, 1988: 151; Barros Borgoño, 1918: 180-184). El acuerdo Matta-Cano llenaba pues las pretensiones de la oposición dominante en Sucre en cuanto a que ambas partes convenían en hacer de los tratados de paz y transferencia de territorios un todo indivisible con estipulaciones recíprocas e integradas. La nueva forma fue aprobada por mayoría abrumadora por el congreso altiplánico.

Hasta el verano de 1897 perduró el optimismo en relación a los pactos firmados, que consideraron además otros convenios referidos a créditos y entendimientos financieros complementarios. Si el optimismo decayó rápidamente a partir de allí hasta hacer fracasar los acuerdos logrados fue por una inesperada torsión del parlamento de Sucre. Este, en una moción que el gobierno chileno consideró arrogante y que introducía elementos de incertidumbres inaceptables sobre materias que se encontraban plenamente concordadas y aceptadas bilateralmente en tratados formales, hizo saber a la Moneda que correspondía al poder legislativo boliviano pronunciarse sobre si el puerto y territorios a ofertar por Chile reunían las condiciones establecidas en las convenciones firmadas.

Santiago aclaró que no podía aceptar semejante imposición; ella no le garantizaba el respeto seguro a las reglas del juego convenidas por parte del otro poder contratante. En suma, los pactos zozobraron lastimosamente. De allí en más, los partidarios de la política boliviana perdieron velozmente las posiciones conquistadas con los tratados de 1895 y comenzaron a cederlas en favor de los defensores de la "paz sin puertos" con Bolivia. Tal fue la postura que finalmente se impuso nueve años más tarde con la firma del tratado de paz y amistad de 1904, sorprendentemente acogida por la corriente liberal entronizada en el ejecutivo y en el congreso de Bolivia, la cual se allanó a aceptar realistamente que en Chile campeaba el partido de los intransigentes, firmemente propensos a garantizarle a los poderes políticos de Bolivia que sólo favorecería el libre tránsito de esa nación y le daría otras compensaciones en infraestructura y moneda dura mas no una salida portuaria soberana. En ese marco, la mediterraneidad del altiplano se superaba mediante la técnica ferroviaria, la inversión y las facilidades comerciales más holgadas.

El tratado de citas, rubricado el 20 de octubre de 1904, instituyó en su artículo fundamental que quedarían "reconocidos del dominio absoluto y perpetuo de Chile los territorios ocupados por este en virtud del Artículo 2 del Pacto de Tregua, de 4 de Abril de 1884", dejando, entre otras muchas garantías, establecido "a perpetuidad, el más amplio y libre derecho de tránsito comercial por su territorio y puertos del Pacífico", señaladamente Antofagasta y Arica $^{30}$.

La cuestión marítima, no obstante, resurgió muy pronto con una virulencia desconocida. En 1910, bajo la presidencia de Eliodoro Villanzón, el canciller boliviano Daniel Sánchez Bustamante,

30. Diario Oficial de la República de Chile, núm. 8169, Santiago de Chile, 27 de marzo de 1905. 
en un memorando vibrante dirigido a las cancillerías de Santiago y Lima, reclamó la cesión de un puerto cómodo en el Pacífico y ofreció a ambas bases y compensaciones satisfactorias en una plausible consideración de los intereses marítimos de Bolivia en el diferendo por la posesión de Taca y Arica, que seguía sin resolverse.

En otras palabras, trasformar el arreglo en discusión en trilateral, consiguiendo de Chile y Perú la cesión de un acceso propio cómodo al mar a través de alguna de las dos provincias en disputa (Espinoza Morga, 1965: 317-19; Bolivia. Presidencia de la República, Ministerio de Relaciones Exteriores y Culto, 2004: 9-10). Fracasada la gestión de Bustamante, la cancillería paceña se orientó hacia la confrontación jurídica internacional. En 1919, 1920 y 1921, en las conferencias de París y ante la Liga de las Naciones, en ese orden, Bolivia pretendió infructuosamente obtener la revisión del tratado de paz de 1904 (Abecia, 2004: 10). La Paz, de cualquier forma, vio renacer sus esperanzas en 1920 cuando el encargado del despacho del exterior de Chile, Emilio Bello Codecido, suscribió con su par boliviano un acta que mostraba la intención de Santiago en orden a diseñar un pasillo al norte de Arica, paralelo a la línea del ferrocarril entre ese puerto y La Paz (Bolivia. Presidencia de la República, Ministerio de Relaciones Exteriores y Culto, 2004: 10).

Un acto meramente potencial. La soberanía definitiva de aquel territorio fronterizo seguía siendo un acertijo mientras no se ejecutara el demorado plebiscito. En tanto el referéndum sobre Tacna y Arica se aplazaba y Perú y Chile negociaban buscando atajos, Bolivia mantuvo expectativas de ser parte de alguna de las alternativas en discusión. Así, en noviembre de 1927, Frank Kellog, Secretario de Estado del gobierno estadounidense, que a esa altura se había constituido en arbitro en la controversia por la posesión de Tacna y Arica, fuertemente inclinado a resolverla de una forma que pusiera fin al drama del enclaustramiento boliviano, cursó un memorando a las cancillerías del Mapocho y Torre Tagle ${ }^{31}$ proponiendo que Chile y Perú cedieran los derechos, títulos e intereses que mantuvieran sobre las dos provincias en litigio, a Bolivia. Resolver la cuestión del Pacífico, en suma, entregándole Tacna y Arica a aquella (Téllez, 1988: 188).

No obstante que el gobierno chileno se mostró llano a examinar la fórmula avanzada por Kellog, el de Perú la rechazó de plano, considerándose el "pato de la boda"32. Terminaba arreglando el problema generado por Chile y Bolivia sin obtener ganancia territorial alguna, después de haber entregado a la primera la provincia de Tarapacá, a perpetuidad. La firma del tratado de límites del 3 de junio de 1929, que decidió la entrega de Arica a Chile y de Tacna a Perú no sólo enterró la solución elaborada por Kellog. Un protocolo adicional al tratado asentó que los distritos cedidos por Perú a Chile -Arica y Tarapacá- no podían ser transferidos un tercero ${ }^{33}$.

31. Así se designa eufemísticamente al ministerio de relaciones exteriores del Perú que tiene su sede principal en el antiguo palacio colonial que perteneciera a José Bernardo de Tagle Bracho y Pérez de la Riva.

32. Expresión equivalente a "chivo expiatorio".

33. Diario oficial de la república de Chile, núm. 15449, Santiago de Chile, 16 de agosto de 1929. 
Cualquier solución futura del enclaustramiento boliviano que contemplara, como en los pactos de 1895 y en el Acta Bello-Gutiérrez, un enclave o pasillo soberano entre la Línea de la Concordia (la nueva frontera reconocida por Perú y Chile) y el río Loa, quedaba sujeto al juicio y al poder de decisión del Estado peruano. Como quiera que fuese, la fórmula esbozada en el Acta Bello-Gutiérrez de 1920 no quedó descartada del todo por la clase política chilena. En el hecho, el gobierno del presidente Gabriel González Videla, imbuido de la aspiración de hacer de Arica un centro de integración política y económica americana, se atrevió a revivirla en 1950, delineando un plan que consideraba la cesión a Bolivia de un corredor soberano de diez kilómetros de ancho, entre el límite de la frontera común por el este, hasta el mar, sin demandarle a La Paz compensaciones territoriales.

Esa "primavera marítima", que en un momento contó con la simpatía abierta del presidente de los Estados Unidos de América, Harry Truman, quien se mostró decidido a apoyar financieramente el proyecto Arica, no perduró (González Videla (1975: 893) ${ }^{34}$. La posibilidad de revivirla se frustró en 1962, año en que la presidencia de Víctor Paz Estenssoro decidió romper relaciones con la república de Chile, que resolvió la intervención y desvió las aguas del fronterizo río Lauca, para fines agrícolas, medida repugnada por la administración boliviana que cuestionaba de plano puesto que, sostenía, el origen de ese río se hallaba dentro de su frontera sur-oeste. Recién en 1975 reflotó de nuevo la "política boliviana".

Ese año, Santiago le planteó a su contraparte paceña la reanudación de relaciones y la apertura de negociaciones en torno a un plan semejante en muchos puntos al presentado en 1950 pero con compensaciones territoriales. Aceptado inicialmente por el gobierno boliviano de Hugo Banzer, no hubo de consumarse, sin embargo. Una súbita contra-propuesta de Lima, a quien en razón del protocolo de 1929 debía consultarse, planteó hacer del puerto de Arica un polo tripartito, rechazada enérgicamente por la cancillería chilena, lo que dejó en punto muerto la negociación. La nueva frustración se cobró con otra ruptura por Bolivia de sus relaciones con Chile en $1978^{35}$.

Los últimos treinta años se han gastado en resbalosos intentos de reencuentro, negociaciones secretas y soluciones que no coagulan. La resolución 426 de la OEA emitida en su 10ª . Asamblea General, en 1979, presentó la cuestión marítima como de preocupación hemisférica y exhortó a darle una solución bilateral que restituyera una salida oceánica completamente soberana a Bolivia. Fue en medio de este nuevo clima internacional que se produjo el denominado enfoque fresco (1986-87), negociación malograda que por primera vez contempló, por lo menos en los planteamientos, la eventualidad de ceder a la nación menos favorecida un enclave

34. Cfr. para una visión global del lado boliviano de la negociación a Luis Fernando Guachalla (1976).

35. La evaluación boliviana en términos generales en Guevara Arze (1978). La chilena está bien documentada en: Chile, Ministerio de Relaciones Exteriores: Historia de las negociaciones chileno-bolivianas, 1975-1978 (el ministerio) (1978). 
marítimo en tres puntos de la costa chilena que quedaban al margen de la restricción fijada por el tratado de $1929^{36}$.

Después de este nuevo traspié, se produjeron otros tantos en el curso de los sucesivos intentos que proliferaron a lo largo de la década de 1990, luego de la normalización democrática que experimentaron ambas repúblicas. No obstante, siguiendo las recomendaciones de la OEA, Chile se allanó a discutir una agenda mutua "sin exclusión alguna", en lo concerniente a mediterraneidad, en una iniciativa directa entre los presidentes Ricardo Lagos y Hugo Banzer (2000-2002). Ese criterio se mantuvo al arrancar el siglo XXI; incluso con la franca predisposición de La Paz, durante las administraciones de Jorge Quiroga y Gonzalo Sánchez de Losada, a concluir un acuerdo con Chile (el Proyecto Pacific LNG), que pretendía la exportación, para el consumo norteamericano, de gas natural boliviano a través de puertos del Pacífico (Bolivia. Presidencia de la República, Ministerio de Relaciones Exteriores y Culto, 2004:14).

El plan consideraba potenciar la intervención y el influjo de Bolivia en dicho litoral mediante la implantación de una zona económica especial, con fuertes garantías para aquella nación; propósito finalmente frustrado por la fuerte oposición que encontró en los cada vez más influyentes movimientos sociales y en las nuevas fuerzas políticas (MAS) anti sistémicas emergentes en el Altiplano. No obstante, en el último lustro, sobre la base de una nueva Agenda de 13 puntos estructurada entre 2006 y 2010 por los gobiernos de Evo Morales y Michel Bachelet, se retomaron las fatigosas tratativas dirigidas a concordar una salida soberana de Bolivia al mar fuere por el ya clásico "pasillo ariqueño" o por un enclave otorgado más al sur, designio que el gobierno chileno de turno (Sebastián Piñera) desechó al reorientar las conversaciones hacia la concesión de facilidades que mejoren la conexión boliviana con el mundo apoyándose en los puertos septentrionales de Chile pero cerrándose de plano a cualquier solución que implique una cesión con soberanía en favor de la nación vecina. La Paz, consiguientemente, se ha reorientado a pedir públicamente la revisión del tratado de 1904 y advertir a Santiago que podría llevar su caso a la Corte Internacional de Justicia, en momentos en que este se encuentra en pleno contencioso con Perú por la delimitación marítima en su frontera norte. Cuadro preocupante, desde luego, para la relación vecinal en el cono sur.

En medio de este panorama histórico desalentador, hemos estimado pertinente explorar otra opción de solución que no pase necesariamente por el tema de la soberanía, piedra de toque

36. Bolivia. Presidencia de la República, Ministerio de Relaciones Exteriores y Culto (2004: 13). El "enfoque fresco" representó una iniciativa que, con el respaldo decidido del gobierno uruguayo, tomó estado en Montevideo entre 1986 y 1987, entrando en los puntos de discusión, aparte de la "solución del pasillo" autónomo inmediatamente al norte de Arica, a solicitud de Bolivia, la alternativa de obtener uno de tres posibles enclaves marítimos: uno en Tarapacá y los restantes en la costa de Antofagasta; cualquiera de ellos cubría una considerable extensión de litoral con una profundidad de varias millas hacia el este, en territorio chileno. La cancillería santiaguina desestimó la propuesta, comprometiendo más que nada una ampliación de los beneficios derivados del tratado de 1904 . 
del problema, pero que resuelva con sentido práctico la más que centenaria reclusión altiplánica. Es lo que esbozaremos a continuación.

\section{EL RÉGIMEN DEL TRATADO ANTÁRTICO Y UNA POSIBLE SALIDA AL MAR PARA BOLIVIA}

El 15 de octubre de 1959 tuvo lugar la Conferencia de Washington que permitió llevar a cabo las negociaciones que dieron vida al Tratado Antártico (en adelante TA). El fin primordial de este tratado es garantizar el uso del territorio antártico exclusivamente para fines pacíficos (artículo I, TA) y a su vez garantizar la libertad y cooperación científica (artículo II, TA). El medio fundamental para el logro de esos fines ha sido la solución establecida en el artículo IV del Tratado, por el cual se regula que: (i) todas las reclamaciones territoriales han sido suspendidas; (ii) ningún acto o actividad constituirá fundamento para hacer valer, apoyar o negar una reclamación de soberanía territorial en la Antártida, ni para crear derechos de soberanía en esa región; y (iii) no se pueden hacer nuevas reclamaciones de soberanía territorial en la Antártida, ni se ampliarán las reclamaciones anteriores, mientras el TA se halle en vigencia.

Ahora bien, dado que sería inaceptable para Chile que su territorio quedara fragmentado o incomunicado entre sí, desde mucho tiempo atrás se ha pensado en darle una salida al mar a Bolivia mediante una franja de tierra que se ubicaría entre la actual frontera con el Perú y la ciudad chilena de Arica. Sin embargo, esto no ha sido posible porque al ser un territorio que antes de la Guerra del Pacífico pertenecía a Perú, cualquier cesión en esa zona debe contar obligatoriamente con el consentimiento peruano de conformidad con el Protocolo Complementario al Tratado de 1929 entre Perú y Chile.

Ante esta situación, surge le pregunta: ¿podría aplicarse un régimen similar al antártico entre Chile, Perú y Bolivia respecto de una franja de tierra ubicada entre la frontera chilena con el Perú y Arica, que le permita la salida al mar a Bolivia? Creemos que sí es posible crear una zona sin soberanía, que denominaremos "Zona Especial", muy parecida a lo que acontece en la Antártida con el Tratado Antártico, pero deben determinarse varios aspectos que complicarían bastante las negociaciones, entre los cuales estarían por lo menos los siguientes:
a. Determinación y duración de la Zona Especial.
b. Fines y mecanismos de protección de la Zona Especial.
c. Jurisdicción y Procedimientos policiales.
d. Símbolos patrios.
e. Intervención de Terceros.
f. Turismo y migración.
g. Protección ambiental.
h. Solución de controversias. 
A continuación vamos a considerar cómo deberían ser abordados cada uno de estos aspectos desde nuestro punto de vista; no sobra recalcar que estos aspectos no son de fácil tratamiento respecto del tema antártico, pero con la voluntad política de los Estados parte del Tratado Antártico se han ido ejecutando y se ha generado un escenario de paz en el continente blanco, aunque haya muchos críticos de los avances reales del Tratado y Sistema Antártico, como Alan Hemmings (2011), quien cuestiona el nivel de cooperación antártica al punto tal que se pregunta por qué se logró una Estación Espacial Internacional antes que una Estación Antártica Internacional. Por supuesto reconocemos que el Tratado Antártico no es el summum maximus de la cooperación internacional para la paz, pero ha sido un mecanismo exitoso durante más de cincuenta años y creemos que su ejemplo sirve de base para nuestra propuesta.

\section{a. Determinación y duración de la "Zona Especial"}

La "Zona Especial" debe ser lo primero a determinar. Dado que el problema fundamental para cualquier negociación territorial concierne a la soberanía, esta Zona Especial debería ser un espacio físico en el cual no podría haber soberanía, como ocurre en la Antártida en virtud del Tratado Antártico. En ese orden de ideas, dicha Zona Especial debería regirse por un planteamiento jurídico similar al contenido en el artículo IV del Tratado Antártico, por lo cual debería considerar al menos los siguientes puntos:

- Que la constitución de la Zona Especial no se puede interpretar como una renuncia a los derechos soberanos territoriales de Chile y de Perú, según sean las circunstancias.

- Ningún acto o actividad constituiría fundamento para hacer valer, apoyar o negar una reclamación de soberanía territorial en la Zona Especial, ni para crear derechos de soberanía en esta región.

En cuanto a qué territorio sería el más apto para la Zona Especial, consideramos que por las disposiciones contenidas en los Tratados limítrofes que Chile ha suscrito con Perú y con Bolivia, lo adecuado sería que la salida al mar a Bolivia que tendría lugar en la Zona Especial fuera una franja terrestre que fuese contigua a la frontera entre Chile y Perú, para no dividir al territorio chileno. Además, la Zona Especial debería tener un ancho adecuado para ejercer funciones de comunicación y transporte de personas y mercancías.

La Zona Especial comprendería entonces sólo una franja de tierra que una la costa con territorio boliviano. El mar frente a la costa quedaría bajo jurisdicción chilena, siempre que se defina así en el juicio que actualmente se adelanta por Perú frente a Chile ante la Corte Internacional de Justicia. En caso que la Corte Internacional de Justicia falle a favor de Perú, la jurisdicción marítima estaría a cargo entonces de ese Estado. 
Las obras de infraestructura para el tránsito de mercancías y/o personas que se efectuarían en la Zona Especial deberían en un principio estar a cargo de Bolivia, quien es la directa beneficiaria de este régimen especial, o también se podría pensar en una empresa tripartita de capital chileno, peruano y boliviano, que construya la infraestructura y opere toda la operación de tránsito desde puerto hasta territorio boliviano.

Ahora bien, en cuanto a la duración, lo ideal sería que la Zona Especial tuviera vocación de perpetuidad, pero bien sabemos que existen muchas aprensiones en Chile sobre cualquier concesión territorial que se le pudiera dar a Bolivia, de manera que se podría plantear un período relativamente corto de unos 5 a 10 años para evaluar el funcionamiento del mecanismo, e irse prorrogando por períodos iguales o superiores de tiempo según se den las circunstancias.

Además, respecto de la duración se debe tener en cuenta que Chile debe tener un derecho preferencial para terminar la Zona Especial cuando esta se utilice de manera inadecuada, como por ejemplo si se utiliza para el tráfico de estupefacientes, de personas, de armas, etc. Es decir, debería establecerse un listado de actividades que no se pueden realizar y que estarían proscritas per se, tal y como lo establece el artículo I del TA, de manera que si Bolivia utiliza inadecuadamente la Zona Especial, Chile la pueda dar por terminada.

\section{b. Fines y mecanismos de protección de la Zona Especial}

En el apartado anterior habíamos mencionado que debería haber un listado sobre las actividades permitidas y prohibidas. Esto se relaciona directamente con el fin primordial de la Zona Especial que sería el uso de una franja de tierra exclusivamente dedicada para permitir el tránsito internacional de personas y mercancías desde un territorio costero hasta Bolivia. En ese sentido, toda actividad diferente al fin primordial quedaría proscrita, especialmente las actividades de tipo militar, actividades de establecimiento y/o asentamiento de personas de cualquier nacionalidad, actividades que afecten el medio ambiente, entre otras.

Para efectos de cumplir con el fin primordial de la Zona Especial se requeriría una institucionalidad ad hoc que permitiría proteger dicho fin. Tal y como ocurre en el régimen antártico, se deberían establecer:

- Una Asamblea Anual de las partes, que sea: (i) un foro político que permita el diálogo político de los Estados parte de la Zona Especial; (ii) un foro de coordinación, ya que este permitiría transmitir los informes de los observadores a los representantes de las Partes y se puede coordinar de esa forma la Zona Especial (como ocurre con la regulación del Artículo IX, numeral 3, Tratado Antártico); y (iii) un foro de regulación, en el cual se tomen medidas regulatorias para las actividades desplegadas en la Zona Especial. 
- Unos Observadores permanentes y otros ocasionales que constaten lo que acontece en la Zona Especial. Los Observadores serían comisiones tripartitas de personas de cada Estado parte, que monitorearían y enviarían informes a la Asamblea Anual y que alertarían a las autoridades policiales o militares en caso de la realización de actividades diferentes al libre tránsito de mercancías y/o personas en la Zona Especial. Los Observadores tendrían unas facultades fiscalizadoras, en el sentido de que se le debe permitir inspeccionar las mercancías que ingresen o egresen de la Zona Especial. Esas facultades de fiscalización se complementarían con las actividades aduaneras que realicen los Estados en el mar territorial, y en territorio boliviano.

\section{c. Jurisdicción y Procedimientos policiales}

El tema de la jurisdicción es uno de los más complejos en el tema antártico. De hecho, como referencia Villamizar (2012), hay casos de delitos en el territorio antártico que no se han podido resolver adecuadamente porque tampoco se ha podido establecer adecuadamente el problema de qué Estado tiene a su cargo la jurisdicción. Además, se debe mencionar que la Antártida, y la Zona Especial que tendría el mismo régimen, al no tener soberanía, surge inmediatamente el cuestionamiento en el sentido de indagar cómo puede haber jurisdicción sin soberanía.

En el régimen del Tratado Antártico, hay un doble régimen que tropieza con el tema de la soberanía. Por una parte, quienes laboran en el territorio antártico como observadores, personal científico y staff de apoyo, se rigen en cuanto a su jurisdicción por su nacionalidad. Respecto del resto de personas, opera el mecanismo de consultas inmediatas, por el cual se busca que las partes del Tratado Antártico se pongan de acuerdo sobre cuál sería la jurisdicción aplicable (Villamizar, 2012).

Tomando la experiencia antártica, los Observadores y el personal de apoyo de estos ubicados en la Zona Especial, que estén debidamente habilitados y acreditados, serían juzgados en caso de alguna conducta punible de conformidad con las leyes y jurisdicción de su nacionalidad. Este es un tema muy controversial, porque si la propuesta que hacemos se encamina a que los Observadores sean una comisión compuesta por un representante de cada uno de los Estados partes, valga decir, un chileno, un peruano y un boliviano, podría ocurrir que si los 3 cometen el mismo delito por los mismos hechos, las condenas o los resultados jurisdiccionales sean diferentes en razón a que cada uno se juzgaría en su país y bajo sus propias leyes. Por supuesto, esta opción es mejor que la de una impunidad absoluta, pero no deja de tener ciertas complejidades.

Por otra parte, emulando al régimen antártico, quien no sea Observador o personal de apoyo, y cometa un delito o alguna falta que sea jurídicamente condenable (como por ejemplo la que realice un operador de transporte o una persona transportada), se debería llamarse a consultas entre los Estados parte de la Zona Especial para determinar de manera rápida qué jurisdicción debe conocer del delito o falta jurídica. 
En cuanto al procedimiento policial, la idea es que los Observadores Permanentes o los ocasionales acudan a un cuerpo policial cuando se percaten de alguna falta. Ese cuerpo policial podría ser trinacional, y su forma de operar sería similar al de la Fuerza de Paz Binacional Cruz del Sur, que actualmente conforman Chile y Argentina; es decir con un Estado Mayor Conjunto que se rota periódicamente entre los Estados miembros, y con una tropa especialmente entrenada para asumir la tarea policial, de manera que ante alguna infracción jurídica que se realice en la Zona Especial puedan proceder a realizar los operativos necesarios para hacer cesar esa infracción y canalizarla jurídicamente en alguna de las jurisdicciones de los Estados parte según corresponda.

\section{d. Símbolos patrios}

Dado que en la Zona Especial no sería posible ejercer soberanía, y a fin de evitar cualquier disputa o acción que pudiere resultar ofensiva a cualquiera de los Estados parte, en esta no se utilizaría ningún tipo de símbolo patrio, y para los efectos de identificación de los Observadores y demás personas o bienes que operen en ella, se crearía y utilizaría un símbolo ad hoc autorizado expresamente por los Estados parte.

\section{e. Intervención de Terceros}

Un aspecto de relevancia concierne a lo que pudieran hacer terceros Estados en la Zona Especial habida cuenta de que en dicha zona no operaría una soberanía. En otras palabras, dado que no hay soberanía cualquier Estado no parte de la Zona Especial podría hacer algún tipo de reivindicación territorial sobre esa zona, o podría aprovecharse de la ausencia de elementos militares para apoderarse de esta.

Para evitar un evento así, y nuevamente emulando el régimen del Tratado Antártico en su artículo X, debería establecerse que cada uno de los Estados parte se comprometería a hacer los esfuerzos apropiados compatibles con la Carta de las Naciones Unidas, con el fin de que nadie lleve a cabo en la Zona Especial ninguna actividad contraria a los propósitos y principios de esta, ni que algún tercer Estado se apropie o haga algún tipo de reivindicación territorial.

\section{f. Turismo y migración}

Tanto del turismo como de la migración habría que hacer una precisión. Si el turismo o la migración fueran para ingresar o salir de territorio boliviano y solo se utiliza la Zona Especial para el tránsito físico, la regla general es que se aplique la legislación boliviana para ingreso y egreso de personas en su territorio. Si el turismo o la migración es para acudir a la Zona Especial como atracción turística o para radicarse, consideramos que dada la naturaleza de la Zona Especial estas actividades no serían posibles, y lo único viable sería que el turismo se hiciera desde alguno de los Estados parte, sin ingresar a la Zona Especial, cumpliendo los requisitos propios del Estado en el que se encuentre quien pretenda hacer turismo. 
Para efectos de migración, es obvio que la Zona Especial no podría ser susceptible de la misma, como ya se mencionó, y si se quiere vivir cerca de la Zona Especial se requeriría cumplir los requisitos migratorios de los Estados parte en el cual se pretenda radicar si se es extranjero. Si se es trabajador o trabajadora de la Zona Especial se debería considerar un régimen especial para estos y sus familias, en caso de que pretendan residir en un Estado parte diferente al de su nacionalidad.

\section{g. Protección ambiental}

Si bien cuando se suscribió el Tratado Antártico se pretendía proteger el medio ambiente antártico, con el devenir de la ejecución del TA se fue haciendo necesario que poco a poco se incorporara una institucionalidad encaminada a proteger dicho medio ambiente, especialmente con el establecimiento del Protocolo de Protección Ambiental, conocido más popularmente como Protocolo de Madrid. En el caso de la Zona Especial somos del criterio de que si se llevase a la práctica debería considerarse, junto con el establecimiento de la misma, un régimen ambiental muy estricto y claro, que al igual que el Protocolo de Madrid contemple regulaciones sobre:

- $\quad$ Prohibición de exploración o explotación de minerales

- Impacto ambiental

- Conservación de fauna y flora

- Conservación y régimen de aguas, así como prevención de contaminación marina

- $\quad$ Eliminación y desecho de residuos sólidos, líquidos y gaseosos

- Responsabilidad emanada de emergencias ambientales.

Además, se debería hacer una proscripción en la Zona Especial de tránsito de material nuclear, y más aún de armas nucleares, de manera que se refuerce y no se eluda en este territorio sin soberanía el Tratado para la Protección de Armas Nucleares en la América Latina y el Caribe (Tratado de Tlatelolco).

\section{h. Solución de controversias}

La solución pacífica de las controversias es un principio universal contenido en el artículo I de la Carta de las Naciones Unidas y replicado en múltiples instrumentos internacionales. En consecuencia, cualquier controversia entre los Estados parte de la Zona Especial debería canalizarse y solucionarse de manera pacífica. Dada la naturaleza de la Zona Especial, es muy probable que se presenten varios diferendos, llevando a que surja la pregunta sobre cuál de los métodos políticos o jurídicos establecidos en Derecho Internacional Público sería el más apto para solucionar las eventuales divergencias, respecto de las cuales se debe considerar que cualquiera de los métodos que se emplee debe ser muy expedito, para evitar afectar el flujo comercial que transita por la Zona Especial. 
En ese orden de ideas, y basándonos en varios de los capítulos de solución de controversias de Tratados de Libre Competencia suscritos por Chile, en caso de controversia las partes afectadas deberán hacer una negociación directa en un lapso breve. Si transcurrido el plazo fijado en el Tratado constitutivo de la Zona Especial no se ha resuelto la controversia, procedería un arbitraje obligatorio y en única instancia, que en un plazo también breve debería proferir el eventual laudo arbitral.

\section{ANÁLISIS POLÍTICO DE LA SITUACIÓN}

Como acabamos de verlo, las relaciones históricas entre Chile, Perú y Bolivia, en lo que concierne el acceso al mar para Bolivia, no han sido exentas, en los últimos 150 años, ni de problemas, ni de tentativas para solucionarlos. Por lo tanto, desde esta perspectiva, y como elemento de contexto de este análisis político del problema, no podemos identificar en la parte chilena una voluntad, constante en el tiempo, de obstaculizar el alcance de una solución real al tema que nos ocupa.

De hecho, los altos y bajos en esta problemática, tienen que ver, habitualmente, con elementos coyunturales de política interna, implicando a actores políticos específicos, tanto chilenos como peruanos o bolivianos - donde los intereses personales superan de lejos el concepto de "bien común" - que presentan diferencias de naturaleza estructural en materia de relaciones internacionales.

Este concepto de bien común, central para la comprensión de los procesos de cohesión social y sus equivalentes político-administrativos, y por lo tanto asociado en forma constante a la gestión política habitual de nuestras naciones, es uno de los pocos conceptos políticos que no se ha modificado desde su origen en la Grecia Antigua, a pesar de las evoluciones sociales, económicas y culturales experimentadas a lo largo de los últimos siglos por las diferentes sociedades. Varios de los otros conceptos políticos estructurando también el mecanismo de la gestión político-administrativa de los grupos sociales cohesionados, por su parte, experimentan, hoy en día, fuertes tensiones de tipo claramente paradigmático.

Es así que el concepto de "ciudadano" gira en torno a una vinculación rígida con una permanencia larga (real o simbólica) en un territorio determinado, frente a nuevas realidades sociales de interculturalidad, de "flujos" o movimientos de personas (incluso extra-territoriales) cada vez más frecuentes e intensos. Lo mismo ocurre con el concepto de "nación" o de "espacio nacional", fuertemente relacionado con una acepción geopolítica de control social de los ciudadanos nacionales, vía una definición de los derechos y responsabilidades que conlleva este estatus político geográficamente determinado, frente al actual movimiento de inclusión económica y luego social, política y cultural, de nuevos ciudadanos cuyo origen de procedencia es extra-nacional. 
En el siglo XXI, la geo-economía le está ganando a la geo-política. Se cuestiona cada vez más abiertamente el vínculo secular, casi naturalizado, que existe todavía formalmente entre el poder político de una nación y su espacio geográfico, a la luz de la crece de un poder asociado a otro tipo de bienes (información, investigación e innovación tecnológica, etc.), cuya fuente se ubica cada vez más en el espacio de las relaciones interpersonales y la interculturalidad. Se cuestiona también el concepto de fronteras como líneas de demarcación entre entidades político-administrativas oficialmente diferenciadas pero con realidades económicas y socio-culturales cada vez más complementarias, cuyo lema es el acercamiento y la integración.

Y se duda cada vez más, también en cuanto a la realidad socio-psicológica de una identidad nacionalizada como representación de un sentimiento de pertenencia sociocultural determinado geográficamente y fijado en el nombre de una nación, frente a realidades de circulaciones territoriales y extraterritoriales que modelan cada vez más fuertemente los vivencias y maneras de pensar de los integrantes de las naciones del mundo, provocando en el mismo tiempo el fortalecimiento de parámetros culturales cada vez más universales.

En este sentido, el concepto de bien común sigue siendo, entonces, un referente inamovible a la hora de justificar, en un marco democrático, un tipo de gestión política en pro de una verdadera cohesión sociocultural. Y de ser así, debe obviamente reflexionarse también en cuanto a su resonancia en materia de política internacional - esta última entendida como la gestión de las relaciones sociales que se dan entre entidades político-culturales diferentes - debido a la crece constante del número de ciudadanos extranjeros en cada territorio político nacional, y cuya función y acción económica legitima política y socialmente su presencia.

Efectivamente, por lógica paradigmática, cualquier proceso político siempre debe corresponder al entorno social y cultural que debe mitigar. Y si el entorno cambia, el proceso político debe adaptarse a la nueva realidad social. En este sentido, el concepto de bien común, por las resonancias filosóficas que incorpora, y como base de un sistema de gestión político-administrativa que apunta a una cohesión social de tipo consensual, como se acostumbra en los países democráticos, debe constituirse en la piedra angular de la totalidad de las relaciones que Chile tiene y debe tener, especialmente con sus vecinos más cercanos al inicio del siglo XXI, o sea en este contexto de modificaciones socioeconómicas, sociopolíticas y socioculturales que conlleva dicho nueva siglo.

En esta realidad intercultural, social, económica y política de mutación, tenemos por lo tanto que adaptar las estructuras existentes a la realidad de nuestro entorno relacional. Esta adaptación es aún más urgente en la medida que se refleja ya la evolución del marco legal que nos rodea a nivel internacional. Es bueno recordar, en este sentido, que el anacronismo, en materia de estructura, de lógica o de poder político, siempre ha sido condenado, y habitualmente más temprano que tarde, por la Historia. 
Por lo tanto, fuerza es también reconocer que en este inicio de siglo XXI se entrega un peso decisional cada vez mayor al concepto de justicia, como base de los procesos que implican los seres y los grupos humanos, en cuanto a la determinación y resolución de los problemas que pueden oponerlos. Desde la protección de las minorías hasta la incorporación de la ética y la igualdad como paradigma de la toma de decisión política, a todo ello nos lleva el actual sentido de la Historia de las relaciones humanas así como su traducción en acción política.

Es claro que este mismo concepto de justicia incluye una subjetividad en cuanto a los parámetros de definición filosófica que en materia de evaluación del "objeto social" implica el diferendo en cuestión. No obstante, en este marco también existe ya un acumulado de experiencias, legitimadas a nivel internacional, que orienta las comprensiones de las situaciones objeto de disputa. Es en este espacio de gestión política de la convivencia a nivel internacional que se ubica el quehacer y la misión de la Corte Internacional de La Haya, actual "censor" del diferendo marítimo que opone Chile y Perú.

Nuestro trabajo se quiere inscribir en este esfuerzo de propuesta de solución a una situación, heredada de relaciones sociales, incluyendo lo político y lo militar, asimétrica, inscritas en el pasado de las relaciones internacionales de Chile, pero cuyas consecuencias sociales, económicas y políticas se hacen sentir hasta el día de hoy.

Utilizando la experiencia ya probada, con éxito, que representa el régimen antártico, símbolo por excelencia de la factibilidad de encontrar soluciones acordes a intereses múltiples, cada vez que existe la voluntad de dialogar en lugar de imponer en forma unilateral, nuestra propuesta, por cierto mejorable, consiste además en gesto de amistad intercultural, contextualizado en la realidad sociopolítica de este nuevo siglo.

\section{REFERENCIAS}

- $\quad$ Abecia Baldivieso, V. (1986). Las relaciones Internacionales en la historia de Bolivia (2 v). La Paz: Los Amigos del Libro.

- $\quad$ Ahumada Moreno, P. (1884). Guerra del Pacífico: recopilación completa de todos los documentos oficiales, correspondencias y demás publicaciones referentes a la guerra, que ha dado a luz la prensa de Chile, Perú y Bolivia, conteniendo documentos inéditos de importancia (Vol. I). Valparaíso: Impr. del Progreso.

- Andaluz Vegacenteno, H. (2002). Bases jurídicas para la reintegración marítima de Bolivia: la regla pacta sunt servanda como punto cero. Santa Cruz: Centro de Publicaciones UPSA. 
- Barros Borgoño, Luis (1918). Los tratados con Bolivia de 1895. Revista Chilena, VI (XVIII), 145- 86.

- Baquijano y Carrillo, J. (1791, 20 de marzo). Disertación histórica y política sobre el comercio del Perú. Mercurio Peruano, I (23).

- $\quad$ Bolivia. Presidencia de la República, Ministerio de Relaciones Exteriores y Culto (2004). La demanda marítima boliviana: El libro azul. La Paz: Dirección de Informaciones de la Presidencia de la República.

- Carlos II (1681). Recopilación de leyes de los reinos de las Indias: mandadas imprimir y publicar por la Majestad Católica del rey Don Carlos II, nuestro señor (4 v). Madrid: Impr. por Ivlian de Paredes.

- Casanovas, O. y Rodrigo, Á. (2005). Casos y textos de Derecho Internacional Público. (5ta. Ed.). Madrid: Editorial Tecnos.

- $\quad$ Chile, Ministerio de Relaciones Exteriores (1978). Historia de las negociaciones chilenobolivianas, 1975-1978. Santiago de Chile: (el ministerio).

- $\quad$ Chile. Departamento de Relaciones Exteriores (1862). Cuestiones de límites entre Chile y Bolivia. En Memoria que el ministro de estado en el departamento de relaciones exteriores presenta al congreso nacional de 1862. Santiago de Chile: Impr. Nacional.

- $\quad$ Diez de Velasco, Manuel (2007). Instituciones de Derecho Internacional Público (16 a ed.). Madrid: Editorial Tecnos.

- $\quad$ Espinoza Morga, O. (1965). Bolivia y el Mar 1810-1964. Santiago de Chile: Nascimento.

- $\quad$ González Videla, G. (1975). Memorias. Santiago de Chile: Gabriela Mistral.

- Guachalla, L. (1976). La Cuestión Portuaria y las Negociaciones de 1950. La Paz: Los Amigos del Libro.

- Guevara Arze, W. (1978). Radiografía de la negociación con Chile. Cochabamba: Universo.

- Hemmings, A.D. (2011). The Antarctic Treaty System (The Year in Review - 2010). New Zealand Yearbook of International Law 8, pp. 238-242. 
- $\quad$ Llanos Mancilla, H (2007). Teoría y Práctica del Derecho Internacional Público. El Estado como sujeto de Derecho Internacional (Tomo II, Volumen 1) (3르 ed.). Santiago: Editorial Jurídica de Chile.

- Montt, M. [1845] (1861). Memoria que el Ministro de Estado en el Departamento de Relaciones Exteriores presenta al Congreso Nacional. Año de 1845. En Memorias del Ministerio de Relaciones Exteriores. 1834-1861. Santiago de Chile: Impr. Nacional.

- Querejazu, R. (2009). Guano, salitre, sangre. Historia de la guerra del Pacífico (la participación de Bolivia). La Paz: GUM.

- $\quad$ Rodríguez Elizondo, J. (2010). Chile - Perú. Temas para después de La Haya. Augusto Pinochet, la Concertación y Sebastián Piñera ante la estrategia peruana. Chile: Planeta.

- Shaw, M. N. (2010). International Law (6 Ed.). New York: Cambridge University Press.

- Tellez, E. (1989). Historia General de la frontera de Chile con Perú y Bolivia 1825-1929. Santiago: Instituto de Investigaciones del Patrimonio Territorial de Chile, Universidad de Santiago de Chile.

- Villamizar, F. (2012). El Tratado Antártico y Mecanismos de Protección del Territorio Antártico. International Law, Revista Colombiana de Derecho Internacional.

- Zimmermann, A., Tomuschat, C., Oellers-Frahm, T. (eds.) (2006). The Statute of the International Court of Justice. A commentary. New York: Oxford University Press.

\section{FUENTES DE ARCHIVO Y DE COLECCIONES OFICIALES}

Abreviaturas empleadas:

RC: Real Cédula

RP: Real Provisión

Leg: Legajo

Lib: Libro

R: Ramo

F: foja

FOL: Folio

FMV: Fondo Morla Vicuña

AAA: Archivo Arzobispado de Antofagasta

AMRE: Archivo del Ministerio de Relaciones Exteriores 
BN: Biblioteca Nacional (Santiago de Chile)

CG: Capitanía General

MIHCh: Manuscritos inéditos para la historia de Chile; Biblioteca Americana de J. T. Medina, Biblioteca Nacional.

\section{Archivo Arzobispado de Antofagasta}

1611/1698 Libro de Varias Hojas repartidas que se recogieron siendo cura propio de este beneficio de Atacama la Baja, el maestro don Bernardo López Sagues...

\section{Archivo General de Indias [Sevilla]:}

Audiencia de Charcas, leg. 438.

Audiencia de Chile, leg. 170, lib. I;

Audiencia de Chile, leg. 67;

Audiencia de Lima, leg. 569, Lib. XI;

Audiencia de Chile, leg. 328, Prevenciones que en cumplimiento del cap. 22 de las instrucciones formadas para el establecimiento de las administraciones generales de los reales derechos de almojarifazgo y alcabalas de la capital de Santiago de Chile y del oficio pasado por el señor contador mayor, don Juan Tomás de Echevers, su fecha 13 de septiembre del presente año de 1777, a consecuencia de la real orden de 6 de abril del citado año, que previene el establecimiento de las administraciones por su real cuenta para la uniformidad del cobro y manejo de dichos ramos a imitación de la capital en todos los corregimientos de esta gobernación, hace el administrador don Ramón del Pedregal y Mollinedo acompañando las citadas instrucciones y demás providencias que gobiernan dicha administración general para el más efectivo logro de las soberanas intenciones.

RC dada en Valladolid de 13.09.1543, Audiencia de Lima, leg. 566, tomo $2^{\text {o }}$

RP expedida en Lima, en 22.05.1561, Patronato, leg. 188 ramo 19

RP expedida en Monzón en 04.10.1563, audiencia de Charcas, leg. 418,lib. I

RP firmada en Madrid, en 16.08.1563, audiencia de Charcas, leg. 418, lib. I

RP de 30.11.1568, Audiencia de Lima, leg.578, lib. I

Patronato, leg. 92, N. 1, R. 1, Información de los méritos y servicios de Pedro de Valdivia, gobernador y capitán general de Nueva Extremadura, y su primer descubridor. El licenciado Gasca le dio en gobernación 41 grados de norte a sur y cien leguas de ancho hueste leste.

Patronato, 185, R. 25, Nombramiento gobernador Santiago a Pedro de Valdivia, Chile, (1541), mientras S.M. proveía otra cosa.

Patronato, leg. 29, R. 1, Auto de la posesión que tomó Pedro de Valdivia, en nombre del emperador Carlos V, en el puerto de Valparaíso, de la provincia de Santiago del Nuevo Extremo o Chile, y de otros pueblos, cuyo descubrimiento había encomendado al capitán Juan Bautista de Pastene, 
piloto del navío "San Pedro", Jerónimo de Alderete y a otros, Valparaíso, 3 de septiembre de 1544.

Patronato, leg. 29, R. 2, Relación de la tierra y costa que descubrió Pedro de Valdivia, electo gobernador y capitán general, en el Nuevo Extremo hasta el Estrecho de Magallanes, en el valle de la Posesión en Copiapó hasta el de Coquimbo; y de la posesión que de ella se tomó. Valparaíso, 3 de septiembre de 1544

\section{Archivo General de la Nación [Argentina]}

Padrón y revisita de Atacama del corregidor Alonso Espejo ordenada por el virrey duque de la Palata, 1683, Sala IX 7.

\section{Archivo Nacional [Santiago de Chile]}

FMV, vol. 29, pza. 2, Nombramiento de gobernador de Chile dado por la Gasca a Pedro de Valdivia, 22 de abril de 1548.

CG: vol. 329; vol. 25, leg. 16

vol. 771, leg. 121 Sobre el nombramiento de Rafael Andreu y Guerrero misionero en charcas, Santiago y otros, 26 de junio de 1802.

AMRE, vol. 63 A, informe del capitán Robert Simpson, comandante de la fragata Chile sobre las operaciones en Mejillones y costa aledaña, Cobija, 20.12.1847

\section{Colección Boletín de las leyes y de las órdenes y decretos del gobierno}

Lib. X, octubre de 1842. Santiago de Chile, Impr. de la Independencia, 1842.

Lib. xxxiv, núm. 12, diciembre de 1866. Impr. Nacional, Santiago de Chile, 1866.

Lib. xliii, núm. 10. 2o vol., octubre de 1875. Santiago de Chile, Impr. Nacional, 1875.

Lib lii,.núm. 12, diciembre de 1884. Santiago de Chile, Impr. Nacional, 1884.

Lib. liii, núm. 5, mayo de 1885. Santiago de Chile, Impr. Nacional, 1885.

Lib. Ixv, núm. 5, mayo de 1895 y Lib Ixiv, núm. 9, septiembre de 1895. Santiago de Chile, Impr. Nacional, 1895.

\section{Archivo Privado E. Téllez L.}

Tratado de alianza defensiva entre las repúblicas de Perú y Bolivia de 6 de agosto de 1873 (mss.). Duplicado extendido por el oficial mayor del ministerio de relaciones exteriores del Perú, M. Sebastián Salazar, Lima, 6 de febrero de 1873.

\section{Biblioteca Nacional de Madrid}

Carta de Juan Lozano Machuca, factor de Potosí, al virrey Martín Enríquez, Potosí, 08.11.1581, J58

\section{Biblioteca Nacional [Santiago de Chile]}

MIHCh, Biblioteca Americana de J. T. Medina, vol. 216, leg. 5547, RC de 01.10.1803 al presidente de Chile comunicando la resolución de poblar el puerto de Paposo. 
Diario oficial de la república de Chile, Santiago de Chile, por Núm. y fecha:

2.129, 21 mayo 1884.

2.289, 4 diciembre 1884.

5298. 31 de diciembre de 1895.

15449, Santiago de Chile, 16 de agosto de 1929.

8169, 27 de marzo de 1905

\section{Palacio Real. Real Biblioteca [Madrid]}

Carta esférica de las costas del reyno de Chile comprendidas entre los paralelos 38 y $22^{\circ}$ de latitud Sur/ Levantada de orden del Rey en el año 1790 por varios oficiales de su Real Armada, presentada a S.M. por mano del Exmo. Señor D. Juan de Langara...; Juan Moreno Tejada la grabó; F. Bauzá la delineó; P. M. Gangoiti la escribió. Chile. E (Costa). Cartas náuticas. 1799. [Madrid: Dirección de Hidrografía], 1799. (S 21ㅇ4'-38o / O 63ㅇ-75202'). (Registro nro. 82620) 